Systematically comparing methods used to study flow in sport: A longitudinal multiplecase study

\author{
Patricia C. Jackman ${ }^{1}$, Lee Crust ${ }^{1}$, \& Christian Swann ${ }^{2}$ \\ ${ }^{1}$ School of Sport and Exercise Science, University of Lincoln, UK \\ ${ }^{2}$ Early Start Research Institute, University of Wollongong, Australia
}

Correspondence concerning this article should be addressed to Patricia Jackman, School of Sport and Exercise Science, Brayford Pool, University of Lincoln, United Kingdom. Email: pjackman@lincoln.ac.uk; Telephone: +441522886680 


\begin{abstract}
Objectives: The study aimed to evaluate the effectiveness of existing methods employed to collect experience-near data on flow in sport to develop a more robust approach to investigate the phenomenon in this context.

Design: Longitudinal mixed method multiple-case study.

Method: Ten Irish athletes $(M$ age $=25.12$ years, $S D \pm 3.83)$ completed the Flow Questionnaire (FQ; Csikszentmihalyi \& Larson, 1984) and the Flow State Scale-2 (FSS-2; Jackson \& Eklund, 2004) following the completion of five competitive performances. Questionnaire responses were used to identify the occurrence of flow and sample individuals for event-focused interviews (total $=22$ ), which were conducted as soon as possible after performances $(M=4.05$ days). Data from the quantitative and qualitative phases were analysed independently prior to integrated dataset analysis using within-case and then crosscase analysis.
\end{abstract}

Results: Flow and clutch states were described by participants during event-focused interviews. Conducting multiple event-focused interviews provided novel insights into similarities and differences in participant experiences across numerous performance contexts. Integration of the questionnaire and interview data revealed issues with the discriminant validity of the FQ and the FSS-2, as the questionnaire contents represented the subjective experience reported by participants during flow and clutch states.

Conclusion: Findings highlight issues with the use of the FQ and FSS-2 to assess the flow experience and reinforce the importance of collecting qualitative data soon after performances until more valid quantitative measures are developed. The methodological issues that emerged are discussed in relation to the existing literature, and potential implications and recommendations for future research are outlined. 


\title{
Systematically comparing methods used to study flow in sport: A longitudinal multiple-
}

\author{
case study
}

\section{Introduction}

Flow is an intrinsically rewarding psychological state involving complete task immersion and the perception that actions occur in a spontaneous and automatic manner (Jackson \& Csikszentmihalyi, 1999). Csikszentmihalyi (2002) conceptualised the flow experience into nine dimensions, and this representation of the phenomenon has been broadly supported by qualitative (e.g., Chavez, 2008; Jackson, 1996; Swann, Crust, Keegan, Piggott, \& Hemmings, 2015) and quantitative (e.g., Aherne, Moran, \& Lonsdale, 2011; Stavrou, Jackson, Zervas, \& Karteroliotis, 2007) studies in sport. Nakamura and Csikszentmihalyi (2002) proposed three of the dimensions as proximal conditions or antecedents of flow, comprising: challenge-skills balance (perceived equilibrium between high skills and demands); clear goals (know what to do); and unambiguous feedback (receive information regarding task progression). Upon satisfying these conditions, it is proposed that individuals enter a subjective experience that can be epitomised by six dimensions ${ }^{1}$ (Nakamura $\&$ Csikszentmihalyi, 2002), including: action-awareness merging (perform automatically), concentration on the task at hand (focus on task), sense of control (e.g., over performance), loss of self-consciousness (reduced concern for self), transformation of time (distorted perception of time passing), and autotelic experience (enjoyable and intrinsically rewarding state). In sport, flow has been associated with superior performance (Jackson \& Roberts,

\footnotetext{
${ }^{1}$ There appears to be a lack of clarity regarding the number of dimensions that must be experienced to constitute a flow experience. For example, Nakamura and Csikszentmihalyi (2002) state that the existence of challengeskills balance, clear goals, and unambiguous feedback leads to the remaining six dimensions of flow. Engeser (2012) postulated that flow is a multifaceted experience, but argued that the autotelic experience could be omitted on the basis that flow can be experienced in activities that might not necessarily be overtly intrinsic in nature (see Engeser \& Schiepe-Tiska, 2012). Moreover, a systematic review of qualitative research on flow in elite sport found that athletes typically report experiencing five of Csikszentmihalyi's (2002) nine dimensions at any particular time during flow (Swann, Keegan, Piggott, \& Crust, 2012). Therefore, there appears to be agreement amongst researchers that flow is multifaceted, but uncertainty regarding the specific number of dimensions required to signify a flow experience.
} 
1992; Swann, Keegan, Crust, \& Piggott, 2016), and a range of positive psychological outcomes, including enhanced self-concept (Jackson, Thomas, Marsh, \& Smethurst, 2001) and well-being (Haworth, 1993). The performance-based and psychological benefits linked to flow emphasise the relevance and desirability of this psychological state for athletes of all levels, and underscores the importance to understanding how athletes can experience this psychological state more consistently, frequently, and intensely during performances (cf. Swann, 2016).

Although there is broad consensus on the definition and conceptualisation of flow, there is less agreement amongst researchers regarding the most valid and reliable method to assess this psychological state (Moneta, 2012). Indeed, Jackson and Kimiecik (2008) outlined that "one of the greatest challenges in flow research or any research involving subjective experiences, is finding ways to assess the experience itself accurately and reliably" (p. 391). To address these methodological challenges, researchers have advocated that collecting data through multiple methods (Jackson, 2014) and minimising the degree of retrospective recall (e.g., Jackson \& Marsh, 1996; Swann et al. 2012) could offer the greatest potential to advance understanding of flow states in sport. Therefore, the aim of this article is to evaluate the effectiveness of existing quantitative and qualitative methods employed to collect experiencenear data on flow in sport to develop a more robust approach to investigate the phenomenon in this context.

\section{Researching Flow in Sport}

A range of methods have been employed to investigate the experience of flow in sport, including experience-sampling, interviews, and questionnaires (cf. Swann, 2016). The Experience Sampling Method (ESM; Csikszentmihalyi \& Larson, 1987) was developed to obtain real-time data about people's experience as it occurred and was "fresh" in their mind. ESM participants are prompted to complete the one-page Experience Sampling Form by 
random beeps on an electronic device (e.g., pager beep) at random intervals throughout each day over a period of time (e.g., one week). Although the ESM, or adapted versions of the ESM, have been employed by some researchers in sport (e.g., Delle Fave, Bassi, \& Massimini, 2003), the impractical nature of wearing an electronic beeper and disrupting an athlete during competitive performance limits the viability of this approach (Jackson \& Kimiecik, 2008). Nonetheless, Csikszentmihalyi (1992) stated that the ESM is "certainly not written in stone" (p. 182), and calls for the development of more pragmatic alternatives to the ESM in sport have been advanced (Jackson, 2014; Swann, 2016).

The majority of studies employ questionnaires to investigate flow (Engeser \& Schiepe-Tiska, 2012). Numerous quantitative measures have been developed to assess the flow experience, although the scales developed by Jackson and Eklund $(2002,2004)$ are the most widely used (Moneta, 2012). The Flow State Scale (FSS; Jackson \& Marsh, 1996), the revised Flow State Scale-2 (Jackson \& Eklund, 2002, 2004), and the abbreviated Short Flow Scale (SFS; Jackson, Martin, \& Eklund, 2008) adopt a componential perspective on flow based on Csikszentmihalyi's (2002) nine dimensions framework. These measures capture experience-near data on the intensity of flow in specific events and are completed soon after performances. The FSS, FSS-2, and the SFS have been used extensively as a measure of flow in sporting activities (e.g., Aherne et al., 2011; Stavrou et al., 2007). Moreover, the scales have been used to assess this phenomenon in other performance domains, including computer gaming (e.g., Harmat et al., 2015) and music (e.g., Wrigley \& Emmerson, 2013).

Despite the prominence of quantitative studies, psychometric inventories struggle to obtain the rich, in-depth descriptions that can be attained through qualitative methods (e.g., Jackson \& Kimiecik, 2008; Swann et al., 2012). To collect richer and more detailed insights, recent qualitative studies have used 'event-focused' interviews to obtain experience-near data on the subjective experience of excellent performance in sport (Swann et al., in press b, 
2016). Based on the purported association between flow and superior performance (e.g., Jackson \& Roberts, 1992), Swann et al. (in press a, in press b) utilised indicators of excellent performance to sample individuals for event-focused interviews. The criteria for excellent performance included tournament victories, personal best performances, or recognition from others (e.g., player of the match award). By conducting interviews soon after recent and specific events, the findings of these studies have provided several important and novel insights. In addition to providing more precise details on flow, the findings suggest that a second, overlapping "clutch" state can be experienced during superior athletic performance (Swann et al., in press a, in press b). This second psychological state is considered to underlie clutch performance (Swann et al., in press a, in press b), a term defined as "any performance increment or superior performance that occurs under pressure circumstances" (Otten, 2009, p. 584). Furthermore, clutch performance represents instances when competitive athletes are successful in pressured situations, are cognisant of the pressure attached to the situation, possess a capacity to experience stress, understand the importance of the outcome, and achieve their success through skilled actions (Hibbs, 2010). Thus, clutch performance is defined in terms of performance outcomes (Hibbs, 2010; Otten, 2009), but clutch states refer to the subjective experience underlying clutch performance (Swann et al., in press a).

Several overlaps in experience were apparent between flow and clutch states (i.e., absorption, altered perceptions, confidence, enhanced motivation, enjoyment, and perceived control), but a number of features distinguished clutch states from flow, comprising: complete and deliberate focus rather than effortless attention; heightened arousal instead of relaxation; and heightened awareness, automaticity of skills, and intense effort compared to automatic and effortless experience (Swann et al., in press a, in press b). Qualitative studies investigating flow in sport have primarily explored the experiences of performers in general throughout their career, and thus adopted a career-based perspective (e.g., Chavez, 2008; 
Jackson, 1996; Swann et al., 2015). Given that evidence of clutch states did not emerge previously, it was suggested that career-based studies might have been unable to identify the subtle differences between these phenomena, and that the description of flow arising from these studies could contain elements of flow and clutch states (Swann et al., 2016, in press b).

The findings of event-focused interview studies (e.g., Swann et al., in press a, in press b) suggest that collecting data soon after recent and specific performances captures more detailed descriptions of athletes experiences. However, as these studies have collected data following a single event, it is not possible to determine whether that experience was consistent with the participant's typical experiences or regarded as a rare, one-off occurrence. A more illuminating approach to investigate similarities or differences in experience between performances could be to qualitatively explore the subjective experience of the same athlete across multiple events (Stavrou et al., 2007; Swann et al., 2016). This refinement of the event-focused interview approach could also be an initial step towards addressing calls to explore the complex interplay between personal and situational factors underlying the occurrence of flow states in sport (Jackson, 2014).

One challenge facing researchers who attempt to conduct event-focused interviews is the identification of suitable criteria to determine the occurrence of flow. Objective markers of excellent performance have been employed previously as the sampling criteria for eventfocused interviews (Swann et al., in press, 2016). However, Jackson (1992) outlined that "while flow is certainly very likely during a personal high, or best performance, it can probably occur to a lesser extent or intensity at other times" (p. 177). Thus, by exclusively focussing on excellent performances, it is possible that briefer or less intense flow states could be overlooked. Given that flow is a subjective experience, an alternative approach to identify the occurrence of flow could be to employ questionnaires to sample individuals for event-focused interviews. The Flow Questionnaire (FQ; Csikszentmihalyi \& Larson, 1984) 
presents quotes describing various dimensions of the flow experience derived from interview data collected during early research by Csikszentmihalyi (1975) and then asks participants to report if they have experienced a similar phenomenon previously. In the event of a positive response, participants are asked to provide information on the type of activities in which this phenomenon was experienced and to describe the characteristics of this psychological state (i.e., thoughts and feelings). The FQ quotes capture the hallmark features that characterise the flow experience and this inventory is considered to be appropriate for identifying the occurrence of flow as it conceptualises flow as a categorical variable (i.e., yes-or-no phenomenon - Moneta, 2012). Therefore, the first two sections of the FQ could be used to identify the occurrence of flow in specific sporting activities to sample individuals for eventfocused interviews.

Although quantitative and qualitative studies have provided important insights on the flow experience, it has been suggested that a mixed method approach could acquire the greatest level and breadth of information on flow (Jackson, 2000). Furthermore, collecting experience-near data on flow through quantitative and qualitative methods could offer opportunities to address further methodological questions in flow research. Acquiring data through the FQ, FSS-2, and event-focused interviews could permit an examination of the effectiveness of the FSS-2 criteria recently suggested to indicate the occurrence of flow (Kawabata \& Evans, 2016). The FSS-2 was designed to assess the intensity of flow and measures flow as a continuous variable (Jackson \& Eklund, 2002, 2004). Kawabata and Evans (2016) attempted to establish criteria to determine the occurrence of flow based on individuals FSS-2 responses. Following latent class factor analysis of FSS-2 responses, the authors suggested that a mean score for the proximal conditions of flow (i.e., challenge-skills balance, clear goals, and unambiguous feedback) of above 3.4 and below 3.3 could be used as criteria to differentiate individuals who experienced flow in the activity from those who did 
not, respectively. Concerns with the use of cut-off points to indicate flow occurrence have been raised (Csikszentmihalyi, 1992) and further examination of the effectiveness of these criteria has been encouraged (Kawabata \& Evans, 2016).

The collection and integration of FSS-2 and event-focused interview data could help to address longstanding calls for further examination of the construct validity of the flow scales by permitting comparison of data obtained through different methods (Jackson \& Marsh, 1996). The contents of the flow scales (Jackson \& Marsh, 1996; Jackson \& Eklund, $2002,2004)$ were informed by findings generated through from career-based interview data (Jackson, 1996). Importantly, these measures were developed prior to the refined understanding about flow and clutch states that has emerged more recently through eventfocused interview studies (Swann et al., in press a, in press b). In light of the overlapping characteristics between flow and clutch states (Swann et al., in press a, in press b), it is possible that contents of the existing flow scales might not solely capture flow, but could also represent some aspects of clutch states. As a result, this has led to calls for systematic investigation of the discriminant validity of the flow scales (Swann, Crust, \& Vella, 2017). Therefore, further examination of the validity of the flow scales is warranted and should account for the perspective emerging from event-focused interview studies by also considering clutch states.

The primary purpose of this study was to empirically examine the effectiveness of existing methods employed to collect experience-near data on flow in sport to develop a more robust approach to investigate this phenomenon. Specifically, this study aimed to: (i) evaluate the effectiveness of collecting data through questionnaires and interviews; (ii) examine the effectiveness of questionnaires to identify the occurrence of flow and sample individuals for event-focused interviews; and (iii) examine the effectiveness of longitudinal data collection. In turn, this study sought to address the limitations of previous studies and answer calls for 
systematic comparison (Jackson \& Marsh, 1996) and refinement of methods employed to study flow in sport (e.g., Jackson, 2014; Jackson \& Kimiecik, 2008; Swann et al., 2012), and further examination of the validity of existing measures of flow (Swann et al., 2017).

\section{Method}

\section{Design and Approach}

Case study research is a method of empirical inquiry that seeks to investigate contemporary social phenomena within a real-world context (Yin, 2014). Studying multiple cases permits investigation of similarities and differences between cases, which can lead to more robust and reliable evidence (Baxter \& Pack, 2008). The present study employed a multiple-case study design to examine the effectiveness of various methods to investigate flow in sport. A fundamental feature of case study research is the collection of data through multiple sources (Yin, 2014). Although the use of mixed methods is a point of debate (e.g., Sparkes, 2015) and presents ontological and epistemological complexities (McGannon \& Schweinbenz, 2011), a pragmatic stance to the use of mixed methods (Giacobbi, Poczwardowski, \& Hager, 2005; Onwuegbuzie \& Leech, 2005) was adopted. A mixed method approach was selected to acquire greater variety and types of information on the subjective experience of participants (cf. Jackson, 2000) and to permit comparison between quantitative and qualitative methods used to capture experience-near data on flow in sport.

The study combined the explanatory sequential (quan $\rightarrow$ QUAL) and the convergent parallel (QUAN + QUAL) mixed method designs. In the explanatory sequential design, the research commences with a quantitative phase, which is followed by a second, qualitative phase that seeks further explanation of the quantitative results (Ivankova, Creswell, \& Stick, 2006). Accordingly, quantitative data were collected in the first phase to inform the sampling of participants for the second, qualitative phase, which helped to elaborate on and explain findings from the quantitative phase. The convergent parallel design simultaneously collects 
quantitative and qualitative data on the same subject to enable the comparison of data collected through different methods (Creswell \& Plano, 2011). Consistent with this design, quantitative and qualitative data were collected in relation to the same performance and analysed independently, before the findings generated from both datasets were merged, compared, and interpreted cohesively. The qualitative methodology was guided by the principles of grounded theory (e.g., Holt, 2016; Holt \& Tamminen, 2010), but a critical version of this methodology (cf. Piggott, 2010) was applied to circumvent the philosophical problems with applying grounded theory (Thomas \& James, 2006). This methodology challenged the researchers to contest pre-existing ideas and reflected the processes employed previously by Swann et al. (in press b, 2015).

\section{Participants}

To optimise the benefits of a multiple-case study design, Stake (2006) recommends the inclusion of between four and ten cases. Ten Irish athletes ( $M$ age $=25.12$ years, $S D \pm$ 3.83) competing in team ( $n=8$; e.g., Gaelic games, basketball) and individual $(n=2$; athletics, endurance running) sports took part in the study. Nine participants were competing in national competitions (e.g., national leagues) and were classified as semi-elite $(n=8)$ and competitive-elite $(n=1)$ based on the proposed taxonomy of expert performance (Swann, Moran, \& Piggott, 2015). One participant was competing in recreational events ( $n=1$; e.g., marathons) but had previously competed in national competitions in another sport. Participants will, hereafter, be represented by a pseudonym and a number representing the event number for each case.

\section{Procedures}

Ethical approval for the study was granted by a school ethics committee at a British university. Upon agreeing to participate, the researcher contacted each participant to discuss the project in more detail. Participants received an email communication, which included a 
unique identity code and an online link to the questionnaire. Collecting questionnaire responses online reflected the difficulties with accessing participants competing simultaneously at different locations. Consistent with previous research (e.g., Wiggins \& Freeman, 2000), participants were asked to complete the questionnaire as soon as possible (i.e., within 24 hours) following five competitive performances (see Pilot study) and provided consent prior to completing the questionnaire ( $M$ assessment period range $=35$ days). All participants completed the required number of questionnaires.

Participants were theoretically sampled for event-focussed interviews in accordance with the principles of event-sampling (Reis \& Gable, 2000) and extreme case sampling (Patton, 2015). A positive response on the FQ was established as the sampling criterion for event-sampling. In accordance with good practice (Eisenhardt \& Graebner, 2007), extreme cases were pursued to explore findings generated in the pilot study (see below) relating to the effectiveness of the proposed criteria for flow occurrence (Kawabata \& Evans, 2016). Three inclusion criteria were specified for extreme case sampling, comprising: (i) indicate a negative response to the FQ; (ii) record a mean score for the proximal conditions of flow equalling or exceeding four on the FSS-2; and (iii) record a mean score for global flow equalling or exceeding four on the FSS- $2^{2}$. Following the identification of cases of interest (event-sampled cases $=25$; extreme cases $=2$ ), the principal investigator contacted the pertinent individuals to request an interview. Upon agreement, interviews were organised and took place as soon as possible after the event (range = same day to seven days later; $M=4.05$ days). A total of 22 interviews ${ }^{3}$ were conducted $(M$ duration $=51.14$ minutes, $S D \pm 13.91)$

\footnotetext{
${ }^{2}$ Although issues were raised in relation to the use of FSS-2 scores to indicate flow occurrence, a pragmatic stance was adopted as this emergent sampling approach sought to explore unusual patterns in the data. The FSS2 criteria were selected in accordance with the instrument measurement labels as scores of four and five indicate that the participants 'agree' and 'strongly agree' that the statement represented their experience (Jackson \& Eklund, 2004).

${ }^{3}$ Five interviews involved the discussion of two performances. This was undertaken at the athletes request due to scheduling constraints. The interview took place within seven days of the first corresponding performance in each instance. To minimise differences with other interviews, the researcher divided the interview into two sections and discussed the performances in chronological order with the same interview guide.
} 
through Skype $(n=16)$ and face-to-face interviews $(n=6)$. Primarily conducting interviews via Skype reflected participant preferences, the desire to collect data soon after the event and the logistical constraints associated with accessing athletes for face-to-face interviews soon after performances. All participants provided written consent to permit an audio recording of the interview. Digital recordings of the interview were transcribed verbatim in preparation for data analysis, while brief notes were taken throughout.

Pilot study. The questionnaire, interview schedule, and sampling protocol for eventfocused interviews were piloted with two female athletes ( $M$ age $=22$ years $)$. The pilot study offered an opportunity to test the data collection procedures and informed the refinement of methods in the final study. Based on procedures adopted in a previous intra-individual, longitudinal study on flow (Wiggins \& Freeman, 2000), participants were asked to complete the questionnaire after five competitive performances. Due to the frequency of positive FQ responses $(5 / 10)$, it was determined that data would be collected at five time points in the final study. Event-focused interviews were undertaken following a positive response to the FQ. Findings generated in the pilot study highlighted areas for further exploration (e.g., comparing different phenomena in the same performance). This process led to the addition of further probing questions in the final interview schedule and an adjustment to the sampling criteria for event-focused interviews to include extreme case sampling. Pilot data were included in the final study on the basis that participants undertook the full procedures employed in the final study.

\section{Data Collection}

Quantitative data collection. The FQ (Csikszentmihalyi \& Larson, 1984) and the FSS-2 (Jackson \& Eklund, 2002, 2004) were completed following each event and were used to assess the occurrence and intensity of flow, respectively. Contents from the first two sections of the FQ (Csikszentmihalyi \& Larson, 1984) were used to assess the occurrence of 
flow in each event. The first section of the FQ features descriptions of flow informed by Csikszentmihalyi's (1975) early work, and the second section asks participants to outline whether or not they have had a similar experience previously. In the current study, participants were asked to read the following quote from the FQ: "I am totally involved in what I am doing. My mind isn't wandering. My body feels good. I am totally focussed but it is not hard to concentrate. I am oblivious to my surroundings. I am performing automatically, without thinking about it. I feel confident." This quote has been used in qualitative research previously to orient participants towards flow (e.g., Jackson, 1996). The next section asked to respond "yes" or "no" to the following question: "During this performance, did you have a similar experience, however brief, at any stage?" This question was amended from the original FQ to ensure that participant responses were anchored to a specific performance.

The FSS-2 (Jackson \& Eklund, 2002, 2004) was used to assess flow intensity in each event. This instrument contains 36 items representing nine subscales, which correspond with the nine dimensions of flow (Csikszentmihalyi, 2002). Each subscale contains four items and participants rated each item on a 5-point Likert scale that ranged from 1 (strongly disagree) to 5 (strongly agree), with a midpoint of 3 (neither agree nor disagree). Assessments of internal consistency and construct validity determined that the FSS-2 is a satisfactory measure of flow, with alpha coefficients ranging from 0.80 to 0.90 (Jackson \& Eklund, 2002).

Qualitative data collection. Qualitative interviews can acquire rich and detailed descriptions of subjective experiences (Smith \& Sparkes, 2016). Interviews were conducted to explore the experience of participants in specific competitive events. An interview schedule was developed based on previous research (e.g., Jackson, 1996; Swann et al., 2016). The semi-structured and open-ended approach adopted by the interviewer facilitated the development of rapport and allowed the interviewee to elaborate and discuss emerging 
themes (cf. Sparkes \& Smith, 2014). During the interview, participants were asked to describe the experience that informed their positive response to the FQ. Participants were then asked to provide a chronological, descriptive account of their subjective experience across the duration of the activity, and probing questions were employed to explore alternations identified in their psychological state (e.g., can you describe your thoughts and feelings before and after that point?). Undertaking preliminary analysis of the questionnaire data prior to conducting interviews permitted the addition of participant-specific probes to individual interview schedules (e.g., "This experience seemed to be very enjoyable. Can you tell me more about that?). Participants were asked if they had anything further to add prior to concluding the interview.

\section{Data Analysis}

Analysis of data took place over two stages in accordance with recommendations for multiple-case study research (Stake, 2006). First, within-case analysis was undertaken to analyse the quantitative and qualitative data. The quantitative and qualitative data were analysed separately in the initial stages, prior to integration of the datasets. Second, crosscase analysis was undertaken to search for similarities and differences within (i.e., multiple performances for the same participant) and between participants. A comprehensive descriptive account was then formulated for each case.

Quantitative analysis. Data were analysed in SPSS 22. Each questionnaire was treated as an individual observation. Responses on the FQ were assessed. Cronbach's alpha $(\alpha)$ was used to examine the internal consistency of the FSS-2 scales and subscales. The internal consistency of the scale and subscales was found to be good (i.e., $\alpha \geq 0.80$ ) in all observations. Mean and standard deviations were calculated for the FSS-2 scale and subscales. The scores for challenge-skills balance, clear goals, and unambiguous feedback were combined to obtain a mean score for the proximal conditions of flow. At this point, the 
FQ and FSS-2 data were examined to classify cases that satisfied the sampling criteria for event-focused interviews.

Qualitative analysis. A team approach was employed to guide the analysis of qualitative data. Multiple readings of each interview transcript were undertaken by the first author (i.e., principal investigator) to aid case familiarisation through the process of "indwelling” (Maykut \& Morehouse, 2002). A process similar to that specified by Braun, Clarke, and Weate (2016) was used to guide the analysis. The transcripts were examined for quotes that described the participant's experience during the activity and to identify periods in the performance that informed their positive response to the FQ quote. The selected quotations were used to produce initial codes, which were then inductively analysed and combined into more substantive categories, which represented the experience of participants during these periods. The analysis deliberately aimed to avoid fitting data into an existing flow framework (e.g., Csikszentmihalyi, 2002), or presupposing that the subjective experience described by participants during these periods constituted a flow state. The process of constant comparison (e.g., Holt, 2016) was employed during within-case and cross-case analyses to compare incidents (i.e., descriptions of periods that informed the positive response to the FQ) with incidents. This process enhanced the researcher's sensitivity to patterns in the data and permitted exploration of commonalities and variances in the experience of participants between incidents.

Integrated dataset analysis. Consistent with the concurrent design (Creswell \& Plano, 2011), the results from the quantitative phase and the qualitative findings were integrated and compared during data interpretation. The integration of findings involved the comparison of the FQ responses, FSS-2 scores (i.e., scale, subscale, items), and categories and codes for each case. While the quantitative results presented information on the occurrence and intensity of flow, the qualitative findings provided richer and more detailed 
insights into the subjective experience of participants during the event. The process of integrated dataset analysis permitted elaboration of results and discovery of paradoxical findings (cf. Greene, Caracelli, \& Graham, 1989). The quantitative results and qualitative accounts were then re-examined to enable further exploration of incongruent findings between datasets and explicate the results.

\section{Enhancing Trustworthiness}

A number of strategies recommended for case study research (Bassey, 2003) were employed to enhance the quality of data analysis. Collecting data through questionnaires and interviews facilitated prolonged engagement. Investigating the subjective experience of 10 performers across multiple performances enabled persistent observation of emerging issues, and generated a thorough account of each case. Peer debriefing was conducted throughout as the second and third authors provided constant guidance on the research process, critical evaluation of the data, and challenged the researcher's assumptions to ensure that the interpretation resonated with people other than the researcher (Creswell, 2014). This took place during formal meetings of the research team and regular informal discussions. Although peer debriefing was principally concerned with the processes of data collection and analysis, "critical friends" were asked to offer additional insight regarding the results of these procedures (Smith \& Caddick, 2012; Smith, Sparkes, \& Caddick, 2014). All participants received a copy of the interview transcripts and preliminary analysis of their data prior to partaking in an interview ( $M$ duration $=43.76$ minutes; $S D \pm 15.73$ ). These interviews were viewed as an opportunity to acquire further data and insight into the experience of participants (cf. Smith \& McGannon, 2017). More specifically, this process permitted exploration of gaps in understanding of the results and allowed similarities and differences in the subjective experience of participants between performance contexts to be highlighted and 
discussed (e.g., comparing a flow state in one activity to a flow state in another activity). New data generated through this process were included and analysed.

\section{Results and Discussion}

The primary objective of this study was to critically evaluate existing quantitative and qualitative methods used to collect experience-near data on flow in sport. In accordance with the specified rationale for employing mixed methods and recommended practice (e.g., Bryman, Becker, \& Sempik, 2008; Sparkes, 2015), the results of the quantitative and qualitative phases are reported in an integrated manner throughout to facilitate comparison between methods and are presented in terms of: (i) examining the effectiveness of eventfocused interviews to explore optimal experience in sport; (ii) examining the effectiveness of questionnaires to detect flow occurrence; (iii) assessing the validity of the Flow State Scale-2; and (iv) examining the effectiveness of longitudinal data collection. This section draws upon extant literature to critically evaluate the methods employed and highlight potential implications for future research.

\section{Examining the Effectiveness of Event-Focused Interviews to Explore Optimal}

\section{Experience in Sport}

Event-focused interviews provided several novel insights regarding the complexity of optimal experience during competitive sport performance. Findings were consistent with previous event-focused interview studies (Swann et al., in press a, in press b, 2016) as participants described flow and clutch states during these performances. A phenomenon reconciling with common understanding of flow (e.g., Chavez, 2008; Swann et al., 2015) was apparent in 21 of the 25 event-sampled cases (84\%). However, an important finding was that 19 of the $27(70 \%)$ event-sampled and extreme cases included a phenomenon that was consistent with the description of clutch states in sport (Swann et al., in press a). Furthermore, 
both flow and clutch states were reported in the same performance in $48 \%$ of event-focused interviews (13/27).

Consistent with the proposed characteristics of these phenomena, experiential overlaps and differences were apparent between these states (Table 1). Salient features differentiating clutch states from flow included: complete and deliberate focus compared to effortless attention; absence of negative thoughts in contrast to absence of critical thoughts; heightened arousal rather than relaxation; and automaticity of skills, heightened awareness, and intense effort instead of automatic and effortless experience. While acknowledging the common characteristics of both states, a noteworthy finding was that participants could identify and explicate contrasts in their experience between flow and clutch states. The mutual exclusiveness of flow and clutch states was highlighted when athletes reported each state at separate points in the same activity, and the findings supported the perspective that athletes experience flow or clutch states but cannot experience both states simultaneously (Swann et al., in press b). For example, Kate (2) compared the effortless attention and automatic and effortless experience during flow to the complete and deliberate focus, heightened awareness, and intense effort that characterised her experience when transitioning into a clutch state at a later stage in the event:

The first bit [i.e., flow] was about getting myself into rhythm...your body moves in perfection, without thinking...I'm not aware of my breathing...I was very much within myself and not aware of things that were around me...it was blissful...While the last part [i.e., clutch] was all about expending everything that I have until the end...the time told me that I was close to my personal best...I really tuned into my breathing. I was aware of who was ahead of me and who was near me...I gave it everything...you are pushing everything in your body. 
Relative to the relaxation concomitant with flow, clutch states were epitomised by heightened arousal, as Sam (2) outlined when reporting both states in the same activity: "there was no tension or stress in the body [during flow]...it [clutch] was not necessarily a relaxed state...there was more tension in the body because you are trying to push yourself." Overall, the findings suggest that event-focused interviews provide more precise details on the psychological states experienced by athletes in sport compared to findings reported in previous career-based interview studies on this topic (e.g., Chavez, 2008; Jackson, 1996; Swann et al., 2015).

\section{[INSERT TABLE 1 ABOUT HERE]}

\section{Examining the Effectiveness of Questionnaires to Detect Flow Occurrence}

A primary objective of this study was to extend the sampling approach used in previous event-focused interview studies (e.g., Swann et al., in press b, 2016) by examining the effectiveness of questionnaires to detect the occurrence of flow and sample individuals for event-focused interviews. The following sections present findings regarding the effectiveness of the FQ (Csikszentmihalyi \& Larson, 1984) and the FSS-2 criteria proposed by Kawabata and Evans (2016) to detect the occurrence of flow.

Flow Questionnaire. A positive response to the FQ was provided in half of the investigated performances (25/50). Analysis of the interview data revealed that a psychological state reconciling with common descriptions of flow (e.g., Chavez, 2008; Swann et al., 2015) was described in $84 \%(21 / 25)$ of events in which participants indicated a positive response to the FQ. A noteworthy finding was that cases deemed to be incongruent with flow as well as the two extreme cases contained phenomena that reconciled with the description of clutch states (Swann et al., in press a). The most salient features that differentiated clutch states from flow included intense effort, heightened awareness, and complete and deliberate focus: "It was close...I knew I was in a real game... It took effort. It 
took focus" (John, 5). Table 2 illustrates that the FQ contents represented the experience of participants reported during flow and clutch states. Taken together, the findings suggest that the FQ can detect the occurrence of flow and clutch states, and thus raises issues with the discriminant validity of the FQ quote employed.

\section{[INSERT TABLE 2 ABOUT HERE]}

Flow State Scale-2. The proposed criteria for indicating the occurrence of flow based on FSS-2 scores (i.e., $M$ proximal conditions of flow $\geq 3.4$ - Kawabata \& Evans, 2016) was satisfied in $92 \%(46 / 50)$ of performances. However, as outlined in the previous section, only 21 of the 50 investigated performances $(M$ proximal conditions of flow $=4.24, S D \pm 0.39)$ reported a positive response to the FQ and described a flow state during the corresponding event-focused interview. The suggested criteria for flow occurrence was satisfied in $84 \%$ $(21 / 25 ; M$ proximal conditions of flow $=3.82, S D \pm 0.47)$ of performances in which participants provided a negative response to the $\mathrm{FQ}$, or indicated a positive response to the FQ but did not describe an experience that reconciled with flow during the follow-up interview. Overall, the evidence indicates that the criteria suggested by Kawabata and Evans (2016) was unable to distinguish individuals who experienced flow from those who did not in the current study.

\section{Assessing the Validity of the Flow State Scale-2.}

Systematically comparing the qualitative and quantitative data for each case revealed issues with the discriminant validity of the FSS-2. The previous sections outlined that participants reported flow and clutch states during event-focused interviews. In comparing the FSS-2 subscale descriptions (e.g., Jackson \& Csikszentmihalyi, 1999) with the qualitative data, it was apparent that the FSS-2 contents represented participant descriptions of flow and clutch states, thus raising questions with the discriminant validity of the FSS-2 as a measure of flow. Table 3 displays cases in which performers generally "agreed" or "strongly agreed" 
(i.e., $4 \leq M \leq 5$ ) that their experience during the activity was reflected by the FSS-2 subscale. However, the example codes presented relate to the subjective experience reported by participants during clutch states in the corresponding cases, thus demonstrating that the FSS2 subscales did not exclusively capture flow but also represented the experience reported by participants during clutch states.

\section{[INSERT TABLE 3 ABOUT HERE]}

Merging of the datasets revealed that the majority of FSS-2 items could represent the experience reported during clutch states. The following sections outline validity concerns pertaining to each FSS-2 subscale that emerged following the systematic comparison of the FSS-2 and event-focused interview data. Table 4 provides an example item from each subscale in which participants "agreed" or "strongly agreed" that the item statements represented their experience during the events, but presents example codes that describe the subjective experience of participants during flow and clutch states reported in the corresponding performances. The findings demonstrate that the FSS-2 item statements represented the experience of participants during flow and clutch states.

\section{[INSERT TABLE 4 ABOUT HERE]}

Challenge-skills balance. The item statements for this subscale assess the performers perceived level of belief in their ability to match the high challenge posed by an activity. Confidence emerged as a common feature of flow and clutch states. Although challengeskills balance is considered the "golden rule" of flow (Jackson \& Csikszentmihalyi, 1999, p. 6), performers also discussed a feeling of confidence to meet the demands of a challenge during clutch states: "I knew it was going to be a challenge...I just knew that I would do it" (Kate, 4). Findings reconcile with the process of entering clutch states reported previously (Swann et al., in press a), and suggest that the challenge-skills balance subscale captures flow and clutch states. 
Action-awareness merging. During clutch states, performers reported heightened awareness and automaticity of skills: "your awareness rises...I trusted in my skills...I was performing naturally" (Mark, 4). The simultaneous presence of skill automaticity and awareness during clutch states appears to contradict the action-awareness merging dimension of flow (e.g., Jackson, 2014). However, the item statements for this subscale primarily refer to the automatic execution of movement or skills, and could capture the automaticity of skills component of clutch states.

Clear goals. Present findings and previous research (e.g., Swann et al., 2016; in press b) indicate that a distinct type of goal is pursued during the respective states of flow (i.e., open-ended) and clutch (i.e., fixed, measurable), and this subtle difference appears to be a key determinant differentiating flow and clutch states. However, the description of this dimension of flow (e.g., Csikszentmihalyi, 2002) and FSS-2 item statements pertaining to this subscale are primarily concerned with the clarity of goals, and the corresponding item statements represented the type of goals pursued during flow and clutch states. This suggests that further refinement of the flow scales (Jackson \& Eklund, 2004) and the description of this dimension within the conceptualisation of flow (Csikszentmihalyi, 2002) could be warranted to more accurately represent the goals that are most conducive for experiencing flow.

Unambiguous feedback. The item statements pertaining to this subscale evaluate the clarity of feedback and degree of progression (i.e., positive) during the performance, and the contents of this subscale captured the experience of participants during flow and clutch states. For example, Sam (4) outlined that he was "more relaxed and much quicker" during flow, but also reported "good form" during a later clutch state. Clutch performance involves successful performance in pressured circumstances (Hibbs, 2010; Otten, 2009), and the findings 
suggested that item statements pertaining to the unambiguous feedback subscale captured the experience reported by participants during clutch states.

Concentration on the task at hand. Participants reported effortless attention during flow, whereas clutch states were characterised by a complete and deliberate focus. Kate (5) contrasted the type of concentration during flow and clutch states, respectively: "my focus shifted from being effortless to effortful and thinking about one single thought." This FSS-2 subscale contains three items that assess the intensity of focus, and one item measuring the degree of effort required to achieve this intense concentration. The available evidence suggests that the contents of this subscale can represent the effortless attention component of flow, as well as the complete and deliberate focus reported during clutch states.

Sense of control. The item statements for sense of control assess the level of control participants feel over the situation, their actions, and their body. The qualitative findings indicated that perceptions of control were common to flow and clutch states. Consistent with these overlaps, participant responses for both states were captured by the item statements during flow and clutch states.

Loss of self-consciousness. The FSS-2 statements representing loss of selfconsciousness assess the degree of concern individuals have for the opinion of others during the activity. Clutch states were characterised by the absence of negative thoughts, which included the discarding of evaluative concerns: "I had no thoughts about others' perceptions of my performance" (John, 2). This suggests that the items statements pertaining to the loss of self-consciousness could represent the experience of participants during flow and clutch states.

Transformation of time. The distortion of time was reported as an overlapping feature of both flow and clutch states within the altered perceptions category, and both states were represented by the item statements for this subscale. The item statements for 
transformation of time are ambiguous with respect to how an individual's perception of time alters, as one item refers to the acceleration of time (i.e., "it felt like time went by quickly"), whilst a direction is not indicated in others (e.g., "either slowed down or speeded"). Hence, this item appears to be more skewed towards the perceptual acceleration rather than deceleration of time.

Autotelic experience. The autotelic experience subscale includes items that assess the degree of enjoyment reported during (e.g., "I really enjoyed the experience") and after the performance (e.g., "the experience left me feeling great"). Although enjoyment was a characteristic common to flow and clutch states, the qualitative data revealed that the enjoyment associated with clutch states was often recognised after the event (e.g., pride after event completion), and this psychological state was not necessarily considered to be enjoyable during the activity: "Afterwards, I realised that I really enjoyed it, and would be happy to do it again" (Kate, 5). Given that the current items for this subscale assess the degree of enjoyment experienced during and after the event, the evidence suggests that this subscale also represented the experience of participants following clutch states. Furthermore, as the enjoyment linked to clutch states primarily stemmed from the achievement of extrinsic, outcome-oriented goals (e.g., winning), this contradicts Csikszentmihalyi’s (2002) description of the autotelic experience. Hence, this suggests that refinement of the FSS-2 is required to more accurately represent the autotelic experience dimension of flow.

\section{Examining the Effectiveness of Longitudinal Data Collection}

Assessing the psychological state of each case over multiple events generated important and novel insights into similarities and differences in subjective experience between performance contexts. Inspection of the FSS-2 scores revealed variations in flow intensity over the assessment period. However, the interview data generated far richer and more elaborative details regarding the variances in subjective experience across the 
assessment period. Multiple event-focused interviews were conducted with the majority of participants $(n=9)$, and helped to identify consistencies and idiosyncrasies in the experiences of each individual. A variety of situational conditions were present at a macro (i.e., event as a whole) and micro (i.e., within the event) level within each event. Drawing upon qualitative data collected across multiple events facilitated the emergence of patterns regarding the psychosocial interactions and resulting subjective experiences reported by participants in these contexts. Interestingly, participants recognised and explained distinctions in their subjective experience between and within events in response to variations in the performance context. For example, Olivia (5) contrasted situational features across the assessment period and attributed the occurrence of flow in the early stages of her final assessed performance to a reduction in the perception of pressure associated with achieving outcome goals (i.e., winning) in this event:

Everything was much more relaxed this week and there was less pressure on us...In the last three games, we weren't playing as well as a team...we were under pressure...in the last match, we were winning throughout...we were on top as a team.

Interestingly, although Olivia elucidated a reduction in pressure within the macro-context of her final performance, the discontinuation of flow in the second-half of the final event was attributed to an increase in perceptions of pressure in response to situational changes within the micro-context of this performance: "I came out with a different mind-set in the second half...It was a different situation...they had the elements in their favour and we were under a lot of pressure." The novel insights obtained by conducting multiple event-focused interviews highlight the complexity and idiosyncrasy of performance contexts in competitive sport and suggests that longitudinal qualitative data collection could be a valuable way to advance understanding of the psychological states underlying exceptional performance in sport. 


\section{Conclusion and Methodological Reflections}

The purpose of this study was to examine the effectiveness of different methods used to collect experience-near data on flow in sport. Findings support the importance of collecting data soon after performances (e.g., Jackson \& Marsh, 1996; Swann et al., 2012; Swann et al., 2017) and generated valuable insights into the effectiveness of methods used to collect experience-near data in sport. A primary contribution to arise from this study was the identification of issues with the discriminant validity of the FSS-2, as the contents of this measurement tool captured flow and clutch states. This finding supports the perspective that "a gold measurement standard for flow has yet to be reached" (Moneta, 2012, p. 23-24). The present research raises important questions about the field of flow research and provides important insights into the effectiveness of various methods employed to study optimal psychological states in sport. In turn, findings could contribute to the development of more robust methods to help advance understanding of optimal experience in sport.

By collecting data through the FQ, FSS-2, and event-focused interviews, this study attempted to address calls for further examination of the validity of existing quantitative measures of flow (Jackson \& Marsh, 1996; Swann et al., 2017), and the refinement (e.g., Jackson, 2014; Swann, 2016) and systematic comparison of methods (Jackson \& Marsh, 1996) used by flow researchers in sport. In doing so, this process revealed that the contents of the FQ and the FSS-2 appeared to confound flow and clutch states. Given that the contents of both measures were informed by career-based interview data and developed prior to the emergence of the integrated perspective on flow and clutch states in event-focused interview studies (Swann et al., in press a, in press b), it is understandable that these scales captured flow and clutch states. Identifying discriminant validity issues with the FSS-2 could have important implications for the broader literature on flow as the scales developed by Jackson and Eklund $(2002,2004)$ are regarded as the most widely-used quantitative measures 
employed to assess the flow experience (Moneta, 2012). Accordingly, the findings support concerns about existing knowledge of flow (Swann et al., 2017), and suggest that revision of the FSS-2 or development of new measures is required to more accurately represent the flow experience and differentiate this phenomenon from clutch states.

Present findings reinforce the importance of interviews for investigating subjective phenomena (e.g., Jackson \& Kimiecik, 2008; Stavrou et al., 2007), and provided further evidence for the effectiveness of event-focused interviews (e.g., Swann et al., in press a). The current study attempted to extend the sampling approach employed previously by Swann et al. (in press a, in press b, 2016) by evaluating the effectiveness of questionnaires to detect the occurrence of flow and sample athletes for event focused-interviews. Following integrated dataset analysis, the FQ was identified as a more effective tool for identifying the occurrence of flow than the cut-off points on the FSS-2 proposed by Kawabata and Evans (2016). However, present findings suggest that the FQ is not a panacea for event-sampling of flow as the contents of the quote employed also represented some elements of the subjective experience described by participants during clutch states. Therefore, this raises issues with the discriminant validity of the FQ and future research should consider the possibility that this inventory could represent flow and clutch states.

The FSS-2 criteria proposed to indicate the occurrence of flow (Kawabata \& Evans, 2016) was unable to differentiate individuals who did and did not experience flow in the present study. In accordance with the instrument labels, flow is proposed to have been experienced by the respondent when the mean score for the proximal conditions of flow exceeds the midpoint of a scale ranging from one to five by 0.4 units (i.e., $\geq 3.4$ ). Given that the midpoint on this scale is labelled "neither agree nor disagree", it seems questionable to utilise this modest score to indicate the occurrence of flow. This contention is emphasised by findings in the present study as the majority of cases not reporting flow through the FQ or 
event-focused interviews satisfied Kawabata and Evans' (2016) criterion for flow occurrence. Therefore, the current study demonstrates the practical challenges associated with applying cut-off points to indicate the occurrence of flow using a scale that measures this complex phenomenon as a continuous variable.

By conducting multiple rather than single event-focused interviews with each participant, the present study extended the approach employed in previous event-focused interview studies (e.g., Swann et al., in press a). This methodological refinement addressed calls for longitudinal qualitative data collection for the study of optimal experience in sport (e.g., Stavrou et al., 2007; Swann et al., 2016), and helped to identify similarities and differences for each case across the events. Hence, this approach offered novel insights into consistencies and idiosyncrasies in participant experiences that had not emerged in previous event-focused interview studies. Taken together, the findings suggest that multiple eventfocused interviews appear to offer the most effective way at present to study optimal psychological states in sport until more valid psychometric tools are developed.

\section{Limitations and Recommendations for Future Research}

Despite the promise of findings generated, a number of limitations were apparent that could be addressed in further research. Although the delay between data collection and the conclusion of the event was consistent with previous qualitative (Swann et al., 2016), and quantitative studies (Wiggins \& Freeman, 2000), further refinement of this approach could involve the collection of data immediately after the event. Further research employing multiple event-focused interviews could seek to examine individual differences in flow and clutch states in sport. The findings are unique to the current sample of athletes and cannot be generalised to other populations. Further studies are required to investigate whether issues with the discriminant validity of the flow scales (Jackson \& Eklund, 2002, 2004) are replicated across other sport performers, and in other performance domains in which these 
scales have been employed. The results of such endeavours could have important methodological and theoretical implications for the extant literature on flow and future research on optimal experience in sport. Although the interviewer attempted to minimise the potential for bias by asking participants to describe their experience across the duration of the activity, it is possible that participants were influenced by the questionnaire contents or responses. The inherently subjective nature of analysing qualitative data means that the research team's interpretation of data is presented, and others could have arrived at alternative interpretations. 


\section{References}

Aherne, C., Moran, A., \& Lonsdale, C. (2011). The effect of mindfulness training on athletes' flow: An initial investigation. The Sport Psychologist, 25, 177-189.

Bassey, M. (2003). Case study research. In J. Swann \& J. Pratt (Eds.), Educational research in practice (pp. 111-124). London: Continuum.

Baxter, P., \& Jack, S. (2008). Qualitative case study methodology: Study design and implementation for novice researchers. The Qualitative Report, 13(4), 544-559. Retrieved from http://nsuworks.nova.edu/tqr/vol13/iss4/2

Braun, V., Clarke, V., \& Weate, P. (2016). Using thematic analysis in sport and exercise research. In B. Smith \& A. C. Sparkes (Eds.), Routledge handbook of qualitative research in sport and exercise science (pp. 191-205). Abingdon, OX: Routledge.

Bryman, A., Becker, S., \& Sempik, J. (2008). Quality criteria for quantitative, qualitative and mixed methods research: A view from social policy. International Journal of Social Research Methodology, 11(4), 261-276.

Chavez, E. (2008). Flow in sport: A study of college athletes. Imagination, Cognition and Personality, 28, 69-91. doi: 10.2190/IC.28.1.f.

Creswell, J. W. (2014). Research design: Qualitative, quantitative, and mixed methods approaches. Thousand Oaks, CA: SAGE Publications

Creswell, J. W., \& Plano Clark, V. L. (2011). Designing and conducting mixed methods research. Thousand Oaks, CA: SAGE.

Csikszentmihalyi, M. (1975). Beyond boredom and anxiety. San Francisco, CA: Jossey-Bass, Inc.

Csikszentmihalyi, M. (1992). A response to the Kimiecik \& Stein and Jackson papers. Journal of Applied Sport Psychology, 4, 181-183. 
Csikszentmihalyi, M., \& Larson, R. (1987). Validity and reliability of the Experience Sampling Method. Journal of Nervous and Mental Disease, 175, 529-536.

Csikszentmihalyi, M., \& Larson, R.W. (1984). Being adolescent: Conflict and growth in the teenage years. New York, NY: Basic Books.

Csikszentmihalyi, M., (2002). Flow: the classic work on how to achieve happiness. London: Rider Books.

Delle Fave, A., Bassi, M., \& Massimini, F. (2003). Quality of experience and risk perception in high-altitude rock climbing. Journal of Applied Sport Psychology, 15, 82-98.

Eisenhardt, K., \& Graebner, M. (2007). Theory building from cases: opportunities and challenges. Academy of Management Journal, 50(1), 25-32. doi: 10.5465/AMJ.2007.24160888

Engeser, S. (2012). Theoretical integration and future lines of flow research. In S. Engeser (Ed.), Advances in flow research (pp. 187-200). New York, NY: Springer.

Engeser, S., \& Schiepe-Tiska, A. (2012). Historical lines and an overview of current research on flow. In S. Engeser (Ed.), Advances in flow research (pp. 1-22). New York, NY: Springer. Engeser, S., \& Schiepe-Tiska, A. (2012). Historical lines and an overview of current research on flow. In S. Engeser (Ed.), Advances in flow research (pp. 1-22). New York, NY: Springer. Giacobbi, P.R., Jr., Poczwardowski, A., \& Hager, P.F. (2005). A pragmatic research philosophy for applied sport psychology. The Sport Psychologist, 19, 18-31.

Greene, J. C., Caracelli, V. J., \& Graham, W. F. (1989). Towards a conceptual framework for mixed-method evaluation designs. Educational Evaluation and Policy Analysis, 11(3), 255273. doi: $10.3102 / 01623737011003255$

Harmat, L., de Manzano, O., Theorell, T., Hogman, L., Fischer, H., \& Ullen, F. (2015). Physiological correlates of the flow experience during computer game playing. 
International Journal of Psychophysiology, 97(1), 1-7. doi:

10.1016/j.ijpsycho.2015.05.001.

Haworth, J. (1993). Skills-challenge relationships and psychological well-being in everyday life. Society \& Leisure, 16(1), 115-128. doi: 10.1080/07053436.1993.10715445.

Hibbs, D. (2010). A conceptual analysis of clutch performances in competitive sports. Journal of the Philosophy of Sport, 37, 47-59. doi:10.1080/00948705.2010.9714765

Holt, N. L. (2016). Doing grounded theory in sport and exercise. In B. Smith, \& A. C. Sparkes (Eds.), Routledge handbook of qualitative research in sport and exercise (pp. 24-36). Abingdon, OX: Routledge.

Holt, N., \& Tamminen, K. A. (2010). Moving forward with grounded theory in sport and exercise psychology. Psychology of Sport and Exercise, 11, 419-422.

Ivankova, N. V., Creswell, J. W., \& Stick, S. L. (2006). Using mixed-methods sequential explanatory design: From theory to practice. Field Methods, 18(3), 3-20. doi: $10.1177 / 1525822 \times 05282260$

Jackson, S. (1992). Athletes in flow: A qualitative investigation of flow states in elite figure skaters. Journal of Applied Sport Psychology, 4, 161-180.

Jackson, S. (2014). Flow. In R. M. Ryan (Ed.), The Oxford handbook of human motivation (pp. 127-140). Oxford: Oxford University Press.

Jackson, S. A. \& Csikszentmihalyi, M. (1999). Flow in sports. Champaign, IL: Human Kinetics. Jackson, S. A. (1996). Toward a conceptual understanding of the flow experience in elite athletes. Research Quarterly for Exercise and Sport, 67, 76-90. doi: $10.1080 / 02701367.1996 .10607928$

Jackson, S. A. (2000). Joy, fun, and flow state in sport. In Y. L. Hanin (Ed.), Emotions in sport (pp. 135-156). Champaign, IL: Human Kinetics. 
Jackson, S. A., \& Kimiecik, J. C. (2008). The flow perspective of optimal experience in sport and physical activity. In T. S. Horn (Ed.), Advances in sport psychology (pp. 377-400). Champaign, IL: Human Kinetics.

Jackson, S. A., \& Roberts, G. C. (1992). Positive performance states of athletes: Toward a conceptual understanding of peak performance. The Sport Psychologist, 6(2), 156-171.

Jackson, S. A., Thomas, P. R., Marsh, H. W., \& Smethurst, C. J. (2001). Relationships between flow, self-concept, psychological skills and performance. Journal of Applied Sport Psychology, 13, 129-153.

Jackson, S., \& Eklund, R. (2002). Assessing flow in physical activity: The Flow State Scale-2 and Dispositional Flow Scale-2. Journal of Sport and Exercise Psychology, 24, 133-150.

Jackson, S., \& Eklund, R. (2004). The flow scales manual. Morganstown, WV: Fitness Information Technology.

Jackson, S., \& Marsh, H. (1996). Development and validation of a scale to measure optimal experience: The Flow State Scale. Journal of Sport and Exercise Psychology, 18, 17-35.

Jackson, S., Martin, A.J., \& Eklund, R. C. (2008). Long and short measures of flow:

Examining construct validity of the FSS-2, DFS-2 and new brief counterparts. Journal of Sport and Exercise Psychology, 30, 561-587.

Kawabata, M., \& Evans, R. (2016). How to classify who experienced flow from those who did not based on the Flow State Scale-2: A pilot study of latent class factor analysis. The Sport Psychologist, 30(3), 267-275. doi: 10.1123/tsp.2014-0053

Maykut, P., \& Morehouse, R. (2002). Beginning qualitative research: A philosophic and practical guide. London: Falmer Press.

McGannon, K. R., \& Schweinbenz, A. N. (2011). Traversing the qualitative-quantitative divide using mixed methods: Some reflections and reconciliations for sport and experience 
psychology. Qualitative Research in Sport, Exercise and Health, 3(3), 370-384. doi: $10.1080 / 2159676 X .2011 .607187$

Moneta, G. B. (2012). On the measurement and conceptualization of flow. In S. Engeser (Ed.), Advances in flow research (pp. 23-50). New York, NY: Springer.

Nakamura, J., \& Csikszentmihalyi, M. (2002). Positive psychology. In C.R. Snyder \& S.J. Lopez (Eds.), Handbook of positive psychology (pp. 89-105). Oxford: Oxford University Press.

Onwuegbuzie, A. J., \& Leech, N. L. (2005). On becoming a pragmatic researcher: The importance of combining quantitative and qualitative research methodologies. International Journal of Social Research Methodology, 8(5), 375-387.

Otten, M. (2009). Choking vs. clutch performance: A study of sport performance under pressure. Journal of Sport and Exercise Psychology, 31(5), 583-601.

Patton, M.Q. (2015). Qualitative Research \& Evaluation Methods: Integrating Theory and Practice. Thousand Oaks, CA: SAGE Publications.

Piggott, D. (2010). Listening to young people in leisure research: The critical application of grounded theory. Leisure Studies, 29, 415-433.

Reis, H. T., \& Gable, S. L. (2000). Event-sampling and other methods for studying everyday experience. In H. T. Reis, \& C. M. Judd (Eds.), Handbook of research methods in social and personality psychology (pp. 190-222). Cambridge: Cambridge University Press.

Smith, B. \& Sparkes, A. C. (2016). Interviews: Qualitative interviewing in the sport and exercise sciences. In B. Smith, \& A. C. Sparkes (Eds.), Routledge handbook of qualitative research in sport and exercise (pp. 103-123). Abingdon, OX: Routledge.

Smith, B., \& Caddick, N. (2012). Qualitative methods in sport: a concise overview for guiding social scientific sport research. Asia Pacific Journal of Sport and Social Science, 1 (1), 6073. doi: $10.1080 / 21640599.2012 .701373$ 
Smith, B., \& McGannon, K. R. (2017). Developing rigor in qualitative research: problems and opportunities within sport and exercise psychology. International Review of Sport and Exercise Psychology. doi: 10.1080/1750984X.2017.1317357

Smith, B., Sparkes, A. C., \& Caddick, N. (2014). Judging qualitative research. In L. Nelson, R. Groom, \& P. Potrac (Eds.), Research methods in Sports Coaching (pp. 192-201). New York, NY: Routledge.

Sparkes, A. C., \& Smith, B. (2014). Qualitative research methods in sport, exercise and health. Abingdon, OX: Routledge.

Sparkes, A.C. (2015). Developing mixed methods research in sport and exercise psychology: Critical reflections on five points of controversy. Psychology of Sport and Exercise, 16(3), 49-59. doi:10.1016/j.psychsport.2014.08.014

Stake, R. E. (2006). Multiple case study analysis. New York, NY: Guilford Press.

Stavrou, N. A., Jackson, S. A., Zervas, Y., \& Karteroliotis, K. (2007). Flow experience and athletes performance with reference to the orthogonal model of flow. The Sport Psychologist, 21, 438-457.

Swann, C. (2016). Flow in sport. In L. Harmat, F. Ørsted Andersen, F. Ullén, J. Wright, \& G. Sadlo (Eds.), Flow experience (pp. 51-64). Basel, Switzerland: Springer.

Swann, C., Crust, L., \& Vella, S. (2017). New directions for the psychology of optimal performance in sport: Flow and clutch states. Current Opinions in Psychology, 16, 48-53.

Swann, C., Crust, L., Jackman, P., Vella, S., Allen, M., \& Keegan, R. (in press a). Performing under pressure: Exploring the psychological state underlying clutch performance in sport. Journal of Sport Sciences. doi: 10.1080/02640414.2016.1265661

Swann, C., Crust, L., Jackman, P., Vella, S., Allen, M., \& Keegan, R. (in press b). Psychological states underlying excellent performance in sport: Towards an integrated model of flow and clutch states. Journal of Applied Sport Psychology. doi: 10.1080/10413200.2016.1272650 
Swann, C., Crust, L., Keegan, R., Piggott, D., \& Hemmings, B. (2015). An inductive exploration into the flow experiences of European Tour golfers. Qualitative Research in Sport, Exercise and Health, 7(2), 210-234. doi:10.1080/2159676X.2014.926969

Swann, C., Keegan, R. J., Piggott, D., \& Crust, L. (2012). A systematic review of the experience, occurrence and controllability of flow states in elite sport. Psychology of Sport and Exercise, 13(6), 807-819. doi: 10.1016/j.psychsport.2012.05.006

Swann, C., Keegan, R., Crust, L., \& Piggott, D. (2016). Psychological states underlying excellent performance in professional golfers: "letting it happen" vs. "making it happen". Psychology of Sport and Exercise, 23, 101-113. doi: 10.1016/j.psychsport.2015.10.008

Swann, C., Moran, A., \& Piggott, D. (2015). Defining elite athletes: Issues in the study of expert performance in sport psychology. Psychology of Sport and Exercise, 16(1), 3-14. doi: 10.1016/j.psychsport.2014.07.004.

Thomas, G., \& James, D. (2006). Reinventing grounded theory: some questions about theory, ground and discovery. British Educational Research Journal, 32, 767-795.

Wiggins, M., \& Freeman, P. (2000). Anxiety and flow: An examination of anxiety direction and the flow experience. International Sports Journal, 4, 78-87.

Wrigley W. J., \& Emmerson S. B. (2013). The experience of the flow state in live music performance. Psychology of Music, 41, 292-305. doi: 10.1177/0305735611425903

Yin, R. K. (2014). Case study research: Design and methods. Thousand Oaks, CA: SAGE Publications. 
Table 1: The shared and distinct characteristics of the experience of flow and clutch states

\begin{tabular}{|c|c|c|c|}
\hline State & & Categories & Example codes \\
\hline \multirow[t]{10}{*}{$\begin{array}{l}\text { Flow } \\
\text { state }\end{array}$} & \multirow[t]{6}{*}{$\begin{array}{l}\text { Characteristics } \\
\text { shared with } \\
\text { clutch state }\end{array}$} & Absorption & $\begin{array}{l}\text { I was very engaged in the surroundings; completely } \\
\text { immersed in it. }\end{array}$ \\
\hline & & Altered perceptions & $\begin{array}{l}\text { No awareness of time; I can't remember very much } \\
\text { about that section of the course. }\end{array}$ \\
\hline & & Confidence & Full of confidence; feeling of power and confidence. \\
\hline & & Enjoyment & It was really enjoyable; I just enjoyed it much more. \\
\hline & & Motivation & $\begin{array}{l}\text { I was more motivated; you automatically become more } \\
\text { motivated because you want to repeat that success. }\end{array}$ \\
\hline & & Perceptions of control & Felt in control; really controlled in my performance. \\
\hline & \multirow[t]{4}{*}{$\begin{array}{l}\text { Distinct } \\
\text { characteristics }\end{array}$} & $\begin{array}{l}\text { Absence of critical } \\
\text { thoughts }\end{array}$ & $\begin{array}{l}\text { My performance was less analytical; there was no } \\
\text { internal dialogue; no extra mental stress. }\end{array}$ \\
\hline & & $\begin{array}{l}\text { Automatic/effortless } \\
\text { experience }\end{array}$ & $\begin{array}{l}\text { Everything is in sync; you literally just glide; it didn't } \\
\text { feel hard at all; playing on instinct. }\end{array}$ \\
\hline & & Effortless attention & $\begin{array}{l}\text { I didn't have to concentrate as much. It was just coming } \\
\text { naturally; it wasn't an effort to concentrate. }\end{array}$ \\
\hline & & Relaxation & Completely relaxed; no stress or tension in the body. \\
\hline \multirow{12}{*}{$\begin{array}{l}\text { Clutch } \\
\text { state }\end{array}$} & \multirow{6}{*}{$\begin{array}{l}\text { Characteristics } \\
\text { shared with } \\
\text { flow state }\end{array}$} & Absorption & I couldn't tell you who was around me. \\
\hline & & Altered perceptions & It was like waking up. \\
\hline & & Confidence & I just had trust in my ability; I knew I could do it. \\
\hline & & Enjoyment paradox & $\begin{array}{l}\text { There's this enjoyable sadistic thing of going, "my body } \\
\text { hates me". But it's still enjoyable. }\end{array}$ \\
\hline & & Motivation & More motivated; I relished the challenge. \\
\hline & & Perceptions of control & I felt in full control; very composed and in control. \\
\hline & \multirow[t]{6}{*}{$\begin{array}{l}\text { Distinct } \\
\text { characteristics }\end{array}$} & $\begin{array}{l}\text { Absence of negative } \\
\text { thoughts }\end{array}$ & $\begin{array}{l}\text { At no point was there panic; I wasn't worried at any } \\
\text { stage; I didn't second guess myself. }\end{array}$ \\
\hline & & Automaticity of skills & $\begin{array}{l}\text { I came back to not thinking about it again; still } \\
\text { performing very naturally. }\end{array}$ \\
\hline & & $\begin{array}{l}\text { Complete and } \\
\text { deliberate focus }\end{array}$ & $\begin{array}{l}\text { The concentration levels were probably higher; I was } \\
\text { focussed on one single thought; I narrowed my focus. }\end{array}$ \\
\hline & & Heightened arousal & Pumped up; not a completely relaxed state. \\
\hline & & $\begin{array}{l}\text { Heightened } \\
\text { awareness }\end{array}$ & $\begin{array}{l}\text { More calculating and processing; your awareness rises; } \\
\text { it was more analytical. }\end{array}$ \\
\hline & & Intense effort & I was working as hard as I could; giving it everything \\
\hline
\end{tabular}


Table 2: Contents of the Flow Questionnaire quote and examples codes that corresponded with the statements reported during flow and clutch states

\begin{tabular}{l|l|l}
\hline \multicolumn{1}{c|}{ FQ quote statement } & \multicolumn{1}{c}{\begin{tabular}{c}
\multicolumn{1}{c}{ Example codes reported during flow } \\
states
\end{tabular}} & $\begin{array}{l}\text { Example codes reported during clutch } \\
\text { states }\end{array}$ \\
\hline $\begin{array}{l}\text { I am totally involved in } \\
\text { what I am doing. }\end{array}$ & $\begin{array}{l}\text { You are completely immersed; I was } \\
\text { totally engaged in the moment. }\end{array}$ & $\begin{array}{l}\text { Very focussed on my own game and } \\
\text { whatever is around me; totally in the } \\
\text { moment; focussed on the moment. }\end{array}$ \\
\hline $\begin{array}{l}\text { My mind isn't } \\
\text { wandering. }\end{array}$ & $\begin{array}{l}\text { It would have been very hard to distract } \\
\text { me; I'm not paying attention to } \\
\text { anything else. }\end{array}$ & $\begin{array}{l}\text { I was still in the zone; I'm thinking only } \\
\text { of one thing. }\end{array}$ \\
\hline $\begin{array}{l}\text { My body feels good. } \\
\text { surroundings. }\end{array}$ & $\begin{array}{l}\text { It's when your body's moving, when } \\
\text { it's in sync, when it's gliding; I had the } \\
\text { energy; moving more smoothly. }\end{array}$ & $\begin{array}{l}\text { I forgot about anything negative my } \\
\text { body; feeling really good. }\end{array}$ \\
\hline $\begin{array}{l}\text { I feel confident } \\
\text { minutes; everything else around you } \\
\text { becomes a blur; not aware of the things } \\
\text { around me. }\end{array}$ & $\begin{array}{l}\text { Confidence is at an all-time high; } \\
\text { perfect storm of confidence and } \\
\text { composure. }\end{array}$ & $\begin{array}{l}\text { I didn't have time to think about } \\
\text { external distractions; I couldn't tell you } \\
\text { what going on around me. }\end{array}$ \\
\hline $\begin{array}{l}\text { I am performing } \\
\text { automatically, without } \\
\text { thinking about it. }\end{array}$ & $\begin{array}{l}\text { Your body moves in perfection, } \\
\text { without thinking; the decisions are so } \\
\text { quick and you aren't premeditating any } \\
\text { of them, they are just happening. }\end{array}$ & $\begin{array}{l}\text { The skills were very good; I was } \\
\text { running with good form; I was doing } \\
\text { everything well, without thinking about } \\
\text { it. }\end{array}$ \\
\hline $\begin{array}{l}\text { It felt like my concentration was just } \\
\text { coming naturally; my focus seemed } \\
\text { effortless. }\end{array}$ & $\begin{array}{l}\text { The concentration levels were very high; } \\
\text { just focusing on getting to the finish } \\
\text { line. }\end{array}$ \\
\hline
\end{tabular}


Table 3: Sample cases displaying the Flow State Scale-2 subscale scores and qualitative descriptions of clutch states

\begin{tabular}{|c|c|c|c|}
\hline \multirow{2}{*}{$\begin{array}{l}\text { Sample } \\
\text { case }\end{array}$} & \multicolumn{2}{|c|}{ Quantitative data } & \multirow{2}{*}{$\begin{array}{l}\text { Qualitative data } \\
\text { Examples codes reported during clutch states corresponding } \\
\text { with the FSS-2 subscale description }\end{array}$} \\
\hline & FSS-2 subscale & $M$ & \\
\hline John (5) & $\begin{array}{l}\text { Challenge-skills } \\
\text { balance }\end{array}$ & 4.75 & The challenge got greater...you have belief in yourself. \\
\hline Kate (4) & $\begin{array}{l}\text { Action-awareness } \\
\text { merging }\end{array}$ & 4.00 & $\begin{array}{l}\text { It was an effort to perform but it was an unconscious effort... } \\
\text { your mind is so blank when you're doing it. }\end{array}$ \\
\hline $\operatorname{Sam}(2)$ & Clear goals & 5.00 & $\begin{array}{l}\text { Focusing on getting to the line and giving it everything you } \\
\text { have. }\end{array}$ \\
\hline Sam (3) & $\begin{array}{l}\text { Unambiguous } \\
\text { feedback }\end{array}$ & 4.50 & I was thinking "I am in good shape here. I am feeling good." \\
\hline Olivia (1) & $\begin{array}{l}\text { Concentration on } \\
\text { the task at hand }\end{array}$ & 4.50 & We had to concentrate and focus...I got myself into the zone. \\
\hline Kate (2) & Sense of control & 4.25 & I can control what I'm focussing on. \\
\hline Mark (4) & $\begin{array}{l}\text { Loss of self- } \\
\text { consciousness }\end{array}$ & 3.75 & $\begin{array}{l}\text { You don't worry about what managers or other people might say } \\
\text { or think. }\end{array}$ \\
\hline James (5) & $\begin{array}{l}\text { Transformation of } \\
\text { time }\end{array}$ & 3.50 & $\begin{array}{l}\text { Time seems to go quicker... there is very little time to do } \\
\text { anything. }\end{array}$ \\
\hline Kate (1) & $\begin{array}{l}\text { Autotelic } \\
\text { experience }\end{array}$ & 4.25 & It's still enjoyable. \\
\hline
\end{tabular}

Note: The FSS-2 assesses variables on a 5-point Likert scale, comprising: 1 = strongly disagree; $2=$ disagree; 3 = neither agree nor disagree; 4 = agree; 5 = strongly agree. 
Table 4: Sample cases presenting the Flow State Scale-2 item statements and illustrative descriptions of flow and clutch states

\begin{tabular}{|c|c|c|c|c|c|c|c|}
\hline \multicolumn{2}{|c|}{ Flow State Scale-2 } & \multicolumn{3}{|r|}{ Flow state } & \multicolumn{3}{|r|}{ Clutch state } \\
\hline FSS-2 subscale & Example item statement & $\begin{array}{l}\text { Sample } \\
\text { case }\end{array}$ & $\begin{array}{l}\text { FSS-2 } \\
\text { item } \\
\text { score }\end{array}$ & $\begin{array}{l}\text { Example code from qualitative } \\
\text { data }\end{array}$ & $\begin{array}{l}\text { Sample } \\
\text { case }\end{array}$ & $\begin{array}{l}\text { FSS-2 } \\
\text { item } \\
\text { score }\end{array}$ & $\begin{array}{l}\text { Example code from qualitative } \\
\text { data }\end{array}$ \\
\hline $\begin{array}{l}\text { Challenge-skills } \\
\text { balance }\end{array}$ & $\begin{array}{l}\text { I felt I was competent } \\
\text { enough to meet the high } \\
\text { demands of the situation }\end{array}$ & Anne (2) & 4 & $\begin{array}{l}\text { I felt I had the skills to match, if } \\
\text { not better the person I was on. }\end{array}$ & Anne (3) & 5 & $\begin{array}{l}\text { The game is there for the } \\
\text { taking...I felt that was able for } \\
\text { the situation. }\end{array}$ \\
\hline $\begin{array}{l}\text { Action-awareness } \\
\text { merging }\end{array}$ & $\begin{array}{l}\text { Things just seemed to be } \\
\text { happen automatically }\end{array}$ & Sam (3) & 5 & $\begin{array}{l}\text { You aren't thinking about what } \\
\text { you are doing. }\end{array}$ & Helen (2) & 4 & $\begin{array}{l}\text { Once I gained possession, it was } \\
\text { natural. }\end{array}$ \\
\hline Clear goals & $\begin{array}{l}\text { I knew clearly what I } \\
\text { wanted to do }\end{array}$ & Emma (5) & 5 & $\begin{array}{l}\text { In my head I thought "this is like a } \\
\text { drill, you know what to do." }\end{array}$ & Olivia (1) & 5 & We wanted to win. \\
\hline $\begin{array}{l}\text { Unambiguous } \\
\text { feedback }\end{array}$ & $\begin{array}{l}\text { I had a good idea while I } \\
\text { was performing about how } \\
\text { well I was doing }\end{array}$ & Olivia (5) & 5 & I felt myself that I was doing well. & John (5) & 5 & $\begin{array}{l}\text { I was getting into position and } \\
\text { getting on possessions, reading } \\
\text { the play well }\end{array}$ \\
\hline $\begin{array}{l}\text { Concentration on } \\
\text { the task at hand }\end{array}$ & I had total concentration & John (1) & 4 & $\begin{array}{l}\text { All thoughts were on the } \\
\text { performance. }\end{array}$ & Olivia (1) & 5 & $\begin{array}{l}\text { I was in the zone. I got totally } \\
\text { focussed. }\end{array}$ \\
\hline Sense of control & $\begin{array}{l}\text { I felt like I could control } \\
\text { what I was doing }\end{array}$ & Emma (5) & 5 & $\begin{array}{l}\text { Your anticipation is heightened, } \\
\text { you're ready for what is going to } \\
\text { come next. }\end{array}$ & James (5) & 4 & $\begin{array}{l}\text { Very much in control of what I } \\
\text { was going to do. }\end{array}$ \\
\hline $\begin{array}{l}\text { Loss of self- } \\
\text { consciousness }\end{array}$ & $\begin{array}{l}\text { I was not worried about } \\
\text { what others may have been } \\
\text { thinking of me }\end{array}$ & James (5) & 4 & $\begin{array}{l}\text { I didn't care about anything other } \\
\text { than making the right decision. }\end{array}$ & Mark (5) & 4 & $\begin{array}{l}\text { You don't worry about what } \\
\text { managers or other people might } \\
\text { say or think. }\end{array}$ \\
\hline $\begin{array}{l}\text { Transformation of } \\
\text { time }\end{array}$ & $\begin{array}{l}\text { I lost my normal } \\
\text { awareness of time }\end{array}$ & Kate (3) & 5 & $\begin{array}{l}\text { I was totally engaged in the run. It } \\
\text { was very rare that I would have } \\
\text { looked at my watch. }\end{array}$ & Kate (1) & 4 & $\begin{array}{l}\text { I'm not thinking of my time. I'm } \\
\text { thinking, "hit that end line." }\end{array}$ \\
\hline $\begin{array}{l}\text { Autotelic } \\
\text { experience }\end{array}$ & $\begin{array}{l}\text { The experience left me } \\
\text { feeling great }\end{array}$ & Kate (5) & 5 & $\begin{array}{l}\text { Looking back on it, I really } \\
\text { enjoyed it. }\end{array}$ & Mark (5) & 4 & $\begin{array}{l}\text { It gave me a lot of satisfaction } \\
\text { afterwards. }\end{array}$ \\
\hline
\end{tabular}

Note: The FSS-2 assesses variables on a 5-point Likert scale, comprising: 1 = strongly disagree; 2 = disagree; $3=$ neither agree nor disagree; 4 = agree; 5 = strongly agree. 
METHODS TO STUDY FLOW IN SPORT 